\title{
SMST 2021 Conference to be Held in San Diego, California
}

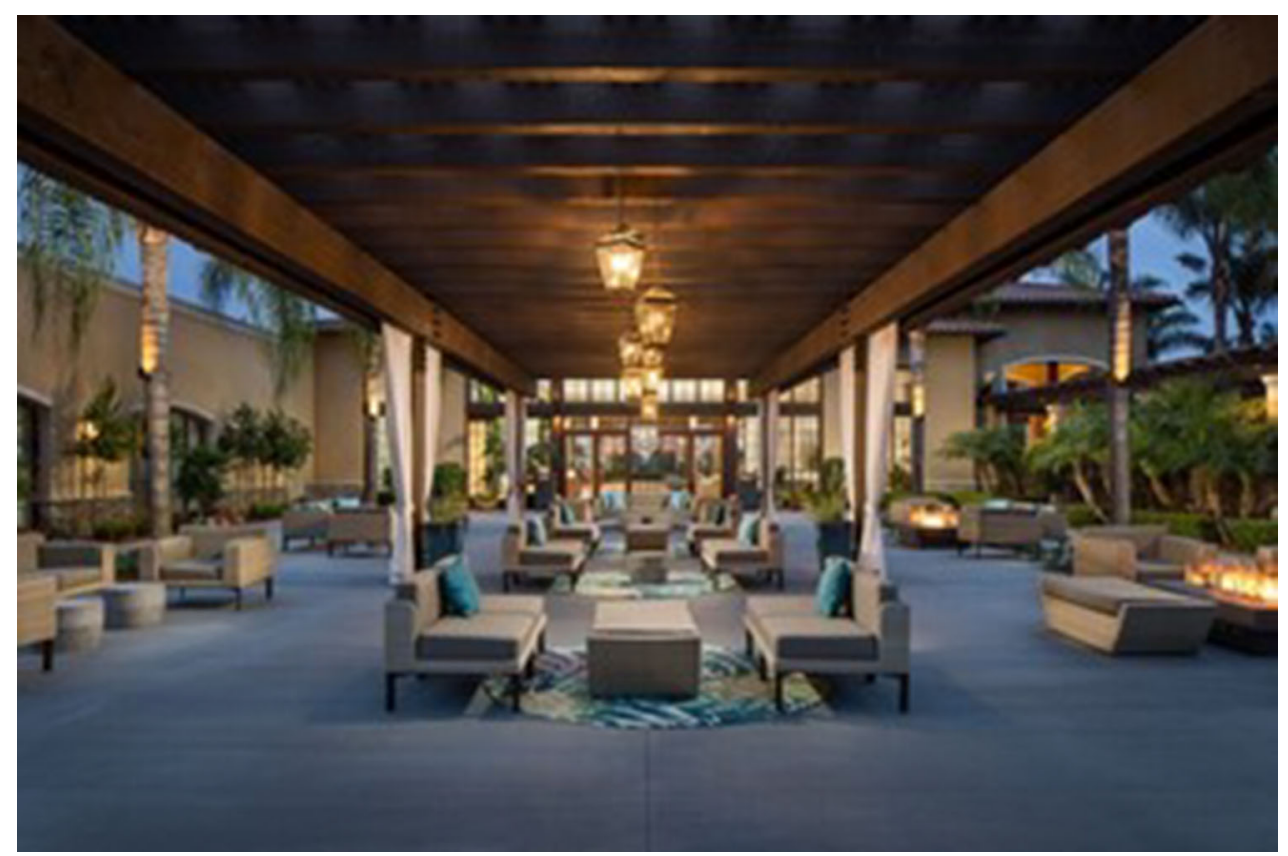

The International Conference on Shape Memory and Superelastic Technologies (SMST) will be held on May 17-21, 2021 at The Westin Carlsbad Resort in San Diego, California. ASM International has been monitoring the development of COVID-19 and assessing its possible impacts on all our organizations' activities. We particularly consult with the Centers for Disease Control and Preven tion $(C D C)$ website, the World Health Organization (WHO) website and our local partners and government. As of this writing, the event will remain on schedule.
SMST is the leading worldwide conference and exposition for the shape memory and superelastic technologies and is highly focused on the manufacturing and application of shape memory materials. If you are looking to improve, design, or apply with Nitinol, you will find the preeminent experts at SMST!

This year's conference will feature an optional all-day course on Nitinol Technology on Monday, May 17, the CASMART 4th Student Design Challenge, and technical sessions held throughout the week. 
The Carlsbad area of San Diego is known worldwide as one of the best tourist destinations with beautiful southern California coastlines, world-class resorts, shopping, golf, restaurants and more.
For more information and to register for SMST 2021, please visit https://www.asminternational.org/web/smst2021/home 